\title{
Hormonal and metabolic response to $12-$ weeks aerobic training in women $(35-50$ years)
}

\author{
Małgorzata Charmas ${ }^{*}$, Benedykt H Opaszowski², Dorota Różańska ${ }^{1}$ and Ewa Jówko ${ }^{1}$ \\ 1Josef Pilsudski University of Physical Education in Warsaw, Poland \\ ${ }^{2}$ Institute of Sport, Warsaw, Poland
}

\begin{abstract}
The aim was to evaluate selected indicators of metabolic and hormonal changes that contributed to maintaining the body's energy balance of women undergoing aerobic practice. Untrained women (35-50 years) participated in 12-week aerobic training. Physiological parameters (glucose, FFA, insulin, leptin, GH, testosterone and cortisol) in the experimental group were analysed. To determine the intensity of exercise, heart rate and lactic acid concentration were recorded.

The 12-week aerobics training resulted in a decrease of glucose, free fatty acids, insulin and cortisol, and an increase of growth hormone, testosterone and leptin in participants. Decrease in glucose, free fat acids, growth hormone, testosterone, cortisol and increase in insulin and leptin were recorded in the control group. The post-exercise value increase in free fat acids, growth hormone $(p<0.05)$ at the beginning, and decrease in glucose, insulin, leptin and growth hormone $(p<0.02)$ at the end of the experiment were observed. No statistically significant post-exercise changes in testosterone and cortisol were noted. Research has shown a tendency to reduce the ongoing cost of the functioning of the organism, while improving physical fitness of women that underwent coaching. The absence of adverse reactions to hormonal balance of anabolic-catabolic, stable energy profile and maintenance of a similar body weight indicate a beneficial health promoting effects of the training and increased exercise tolerance in exercising women.
\end{abstract}

\section{Introduction}

Technological progress caused human physical activity to be limited to a minimum, which in turn induces a serious threat to human health. This applies particularly to greater vulnerability to cardiovascular disease and metabolic diseases, underlying which there are metabolic disorders. The main issue is the problem of overweight, not only in the mature period, but also in the time of biological development, in young individuals. This is linked to progressive tissue insensitivity to insulin in obese individuals, and a whole range of hormonal imbalances deciding on the proper metabolism $[1,2]$, which lies at the basis of balanced diet and exercises. Popular gymnastics with music (so-called "aerobics") as one of the objectives set the regulation of body weight and mainly reduction of excess body fat. "Aerobics" is also the stimulation of the cardio-respiratory system, deciding on the physical capacity and consequently the increase in exercise tolerance and increasing the physiological safety margin.

One of the problems of health training is an appropriate choice of load according to the exerciser's capability, and its duration and frequency. Such training is to have positive health characteristics and should not interfere with the anabolic-catabolic balance appropriate for age and gender. According to the practice of athletic training, the success is determined by such training, which is optimal while maintaining metabolic balance. Therefore, in recent years special significance was given to the research on the influence of exercise on the mechanisms that regulate the proper metabolism. This includes neuroendocrinal regulation, in which a large part is attributed to leptin. This protein synthesized and secreted by adipocytes is important in regulating food intake and basal metabolic rate [3]. Considering the impact on the operation of the central nervous system, leptin can be considered as a kind of barometer of inner energy balance [4]. Regulation of normal metabolism requires the effective functioning of the close interdependence of metabolic pathways, where in addition to said leptin there is a significant share of insulin and its antagonist, the growth hormone [5].

In the evaluation of metabolic balance, the measurements of blood testosterone and cortisol levels provide valuable information about the physiological state of the body during training period, as well as during a single session [6]. Moreover, considering the changes in the concentrations of blood glucose and free fatty acids - metabolic parameters, which are markers of carbohydrate and fat management, can together with the above parameters of endocrine management show a picture of the energy balance status $[7,8]$. Hence, in recent years tests of the influence of exercise on the physiological mechanisms that regulate the metabolism have taken on special significance. Analysis of the different types of physical exercise impact on various parameters of the human body metabolism will allow for creation and modification of the theory of rational assumptions for aerobic training, i.e. a basis for determining the load, intensity, a single dose per session, per week or long-term training.

*Correspondence to: Małgorzata Charmas, Josef Pilsudski University of Physical Education in Warsaw, Poland, Tel: +48-833-428-767; Fax: +48-833-428-800; E-mail: malgorzata.charmas@awf-bp.edu.pl

${ }^{\mathrm{m}}$ : aerobic training, metabolic and hormonal balance, anabolic/catabolic parameters

Received: September 27, 2018; Accepted: October 09, 2018; Published: October 12,2018 
The purpose of this study was to assess selected indicators of metabolic and hormonal changes that contributed to maintaining the body's energy balance in women pursuing the 12-week fitness training with music. It was assumed that the objective of this research will be implemented through the following questions: 1) What is the direction and magnitude of changes in selected metabolic-hormonal parameters under the influence of 12 weeks of aerobic training, and 2) will the 12week aerobic training affect the balance of energy.

\section{Material and methods}

The experiment included 25 females aged 35-50. Women were randomly assigned to an experimental group $(E G, n=13)$ or a control group (CG, $n=12$ ). Participants' characteristics were shown in table 1. The women in the EG group did not actively practice any sports, and they only participated in recreational "aerobics". The women in the CG group did not practice any physical activity. The experiments were approved by the Ethics Committee at the University of Physical Education in Warsaw. The experiment participants were informed of the study aim and methods, and the right to withdraw at any time during the experiment. The participants consented to their participation in the experiment in writing. Before the experiment all participants were asked about their health and physical activity. Based on those data women were disqualified from the groups if they reported using any medicines (even vitamins in huge deals), alcohol (ethanol) intake of more than two drinks a day, smoking and disorders in a menstrual cycle. Parallel with the EG, the study was conducted with the participation of women not participating in training, which formed the CG of similar size, age and degree of their fitness.

Body height was measured by generally accepted method (accuracy $-0.1 \mathrm{~cm}$ ). Body weight was determined using an electronic balance (Tanita BF-666, Japan, accuracy - $0.05 \mathrm{~kg}$ ). Body mass index - BMI $\left[\mathrm{kg} / \mathrm{m}^{2}\right]$ has been calculated based on the following formula $B M I=\frac{m}{h^{2}}$, where $m$ - body weight $[\mathrm{kg}]$ and $h$ - body height $[\mathrm{m}]$.

In each series (I - at the beginning, II - after 6 weeks and III after 12 weeks of the experiment) for the determination of biochemical parameters, blood was collected from the basilic vein $(10 \mathrm{ml})$ and arterialized blood from the fingertip $(70 \mu \mathrm{l})$. The samples were centrifuged, and the resulting serum was stored at $-80{ }^{\circ} \mathrm{C}$ for later analysis. The samples were marked with the following parameters: the arterialized capillary blood: lactic acid (LA) concentration (Hach Lange, Germany; method: LOX-PAP, intra-and interassay coefficient of variation - CV of less than 10\%), and venous plasma: leptin (LEP) (IBL, Germany; method: ELISA; CV < 9\%), insulin (INS) (IBL, Germany; method: ELISA; $\mathrm{CV}<10 \%)$, growth hormone $(\mathrm{GH})$ (IBL, Germany; method: ELISA; CV < 10\%), testosterone (T) (IBL, Germany; method: ELISA; CV < 10\%), cortisol (C) (IBL, Germany; method: ELISA; CV < $10 \%)$, glucose (GLU) (Randox, UK; method: Colorimetric; $\mathrm{CV}<6 \%$ ) and free fatty acids (FFA) (Randox, UK; method: Colorimetric; $\mathrm{CV}<$

Table 1. Characteristic features for the experimental group $(\mathrm{n}=13)$ and the control group $(\mathrm{n}=12)$ at the beginning (I). after 6 weeks (II) and 12 weeks (III) of experiment. IC and IIIC - data for the control group

\begin{tabular}{|c|c|c|c|c|c|}
\hline \multirow{2}{*}{ Parameter } & \multicolumn{3}{|c|}{ Experimental group } & \multicolumn{2}{|c|}{ Control group } \\
\hline & I & II & III & IC & IIIC \\
\hline Age (y) & \multicolumn{3}{|c|}{$40.8 \pm 6.6$} & \multicolumn{2}{|c|}{$43.5 \pm 8.3$} \\
\hline Height $(\mathrm{cm})$ & \multicolumn{3}{|c|}{$164.1 \pm 4.7$} & \multicolumn{2}{|c|}{$163.9 \pm 7.7$} \\
\hline $\begin{array}{l}\text { Body mass } \\
(\mathrm{kg})\end{array}$ & $65.3 \pm 8.9$ & $64.0 \pm 8.6$ & $65.9 \pm 9.1^{*}$ & $67.2 \pm 8.8$ & $68.9 \pm 8.8$ \\
\hline BMI $\left(\mathrm{kg} / \mathrm{m}^{2}\right)$ & $23.7 \pm 3.6$ & $23.2 \pm 2.9$ & $24.1 \pm 3.5$ & $25.0 \pm 3.5$ & $25.6 \pm 3.1$ \\
\hline
\end{tabular}

"value significantly different. $p<0.05$ (II vs. III)
$5 \%)$. In addition, we examined the level of hematocrit and hemoglobin to determine the effect of the hemo-concentration on the concentration size of studied hormonal parameters during the exercise session.

The studied women took part in the 12 -week aerobic training (classes three times a week for $60 \mathrm{~min}$.) carried out by a person qualified to do the program prepared for untrained persons. The program of 60-minute session consisted of: warm up - 10 minutes, aerobic part - 35 minutes, strengthening - 10 minutes and the closing part - 5 minutes. A single training session was carried out according to the scheme, which has been described in detail in our previous work [9]. Effort intensity in the main part (specific aerobics part - Figure 1A) of each session came to on average $145 \mathrm{bpm}$. The intensity in the same part of each session came to on average $160 \mathrm{bpm}$ after 6 weeks of training.

The obtained results were statistically analyzed using Statistica, a program for statistical calculations, version 6.0. For the studied parameters the average values were calculated $(\bar{x})$ with standard deviations (SD) and expressed in the form $\bar{x} \pm S D$, giving additional value ranges. As statistically significant the changes at the level of $p<$ 0.05 were assumed. The fulfilment of the principle of randomization was met on the eligibility of studied women to the experimental and control groups using one-way ANOVA analysis of variance, with which there was no statistically significant differences between parameters such as: body weight $(\mathrm{F}=0.22, p<0.05)$ and parameter $\mathrm{BMI}(\mathrm{F}=0.22$; $p<0.05)$. Deficiencies in the results that emerged due to objective reasons were supplemented using the method of Ferguson-Takane [10]. After checking the coefficient of variation (\%CV) the $\log 10$ data transformation was performed for the checked parameters to normalize their distribution. One-way ANOVA variation analysis was conducted within groups: EG and CG to investigate the significance of differences between the average of I - III test terms described within the experiment. To determine the effect of 12 weeks of EG training in comparison with CG, we analyzed the significance of changes in the average values of the parameters using $t$ test. To analyse the interactions between post-exercise changes in the parameters, Pearson's linear correlation analysis was performed.

\section{Results}

Twenty five women $\left(\mathrm{n}_{\mathrm{EG}}=13, \mathrm{n}_{\mathrm{CG}}=12\right)$ participated in the experiment. Table 1 shows the average values $( \pm \mathrm{SD})$ of parameters characterizing the group. Table 2 shows, in addition to the metabolichormonal parameters tested at rest, also their ranges. Figures 1-9 present the changes of these parameters in a single session at any term of test (I - before the start of the experiment, II - after 6 weeks of the experiment, and III - at the end, i.e. after 12 weeks of the experiment). Analysis of changes in body weight in the experimental group (EG) (Table 1) showed that after 6 weeks of training (test term II) there was a slight decrease $(1.3 \mathrm{~kg}, 1.99 \%)$. However, after 12 weeks of training (test term III) showed a statistically significant increase in body weight ( $1.9 \mathrm{~kg}, 2.97 \%, p<0.05)$ as compared to test term II - Table 1. A similar trend was observed in the control group (CG).

Figure 1A shows the average $( \pm \mathrm{SD})$ course of heart rate (HR) during the hour session of "aerobics" in the three test terms. It was noted that the average value of pulse in exercise in each of the test terms was $130-140 \mathrm{bpm}$, which represents approximately $40-60 \%$ of maximum heart rate for this age group. This also means that the effort was performed at approximately $40-50 \% \mathrm{VO}_{2 \max }$ (Figure 1B).

To determine the nature of the effort during a single session at any time, the concentration of LA was tested (Figure 2). In the case of 

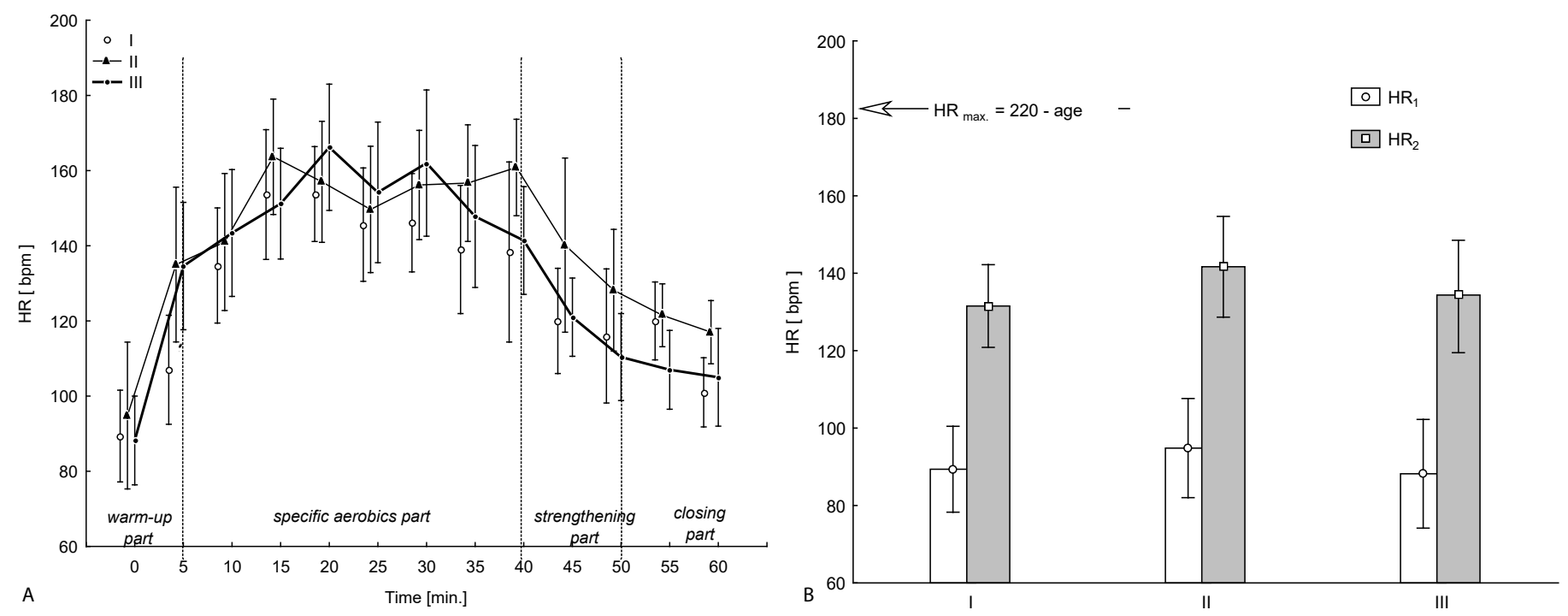

Figure 1. A. Average $( \pm \mathrm{SD})$ changes in heartbeat rate $(\mathrm{HR})$ of the examined women during "aerobic" on three test terms; $\mathbf{B}$. $\mathrm{HR}_{1}-$ heart rate at rest $(\mathrm{x} \pm \mathrm{SD})$ and $\mathrm{HR} \mathrm{R}_{2}-$ average values of 60 minutes of "aerobic" on three test term

I - at the beginning, II - after 6 weeks, III - at the end ( $12^{\text {th }}$ week) of experiment.

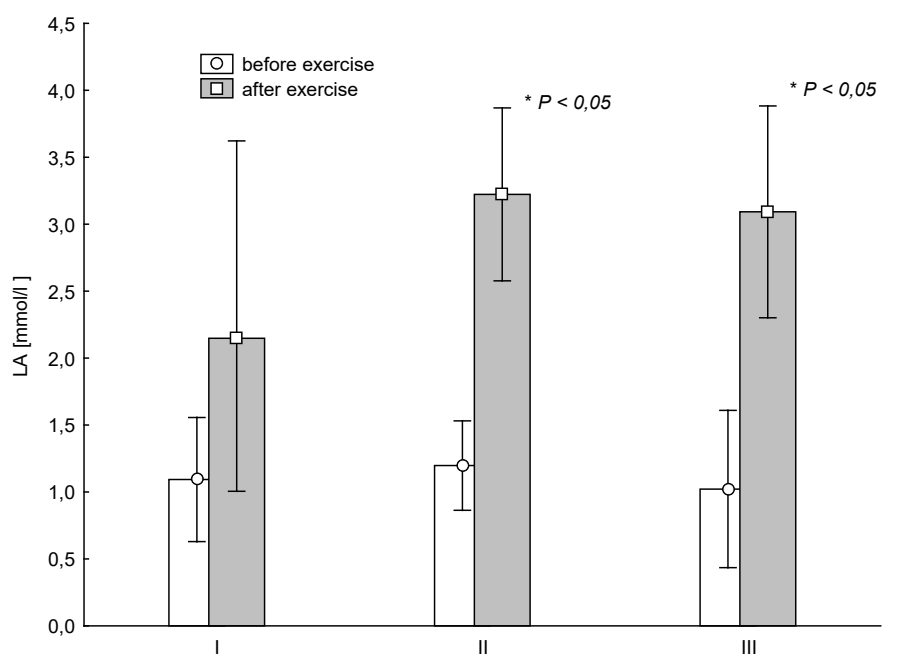

Figure 2. Average $( \pm \mathrm{SD})$ concentration of lactic acid (LA) before and after "aerobics" on three test terms (I, II, III) in the experimental group. I - at the beginning, II - after 6 weeks, III - at the end $\left(12^{\text {th }}\right.$ week $)$ of experiment.

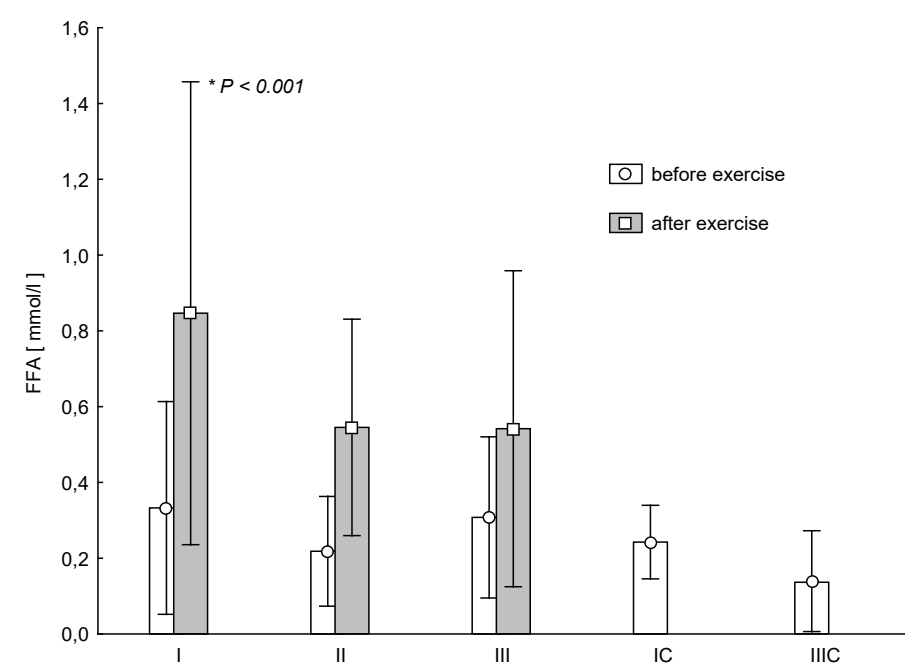

Figure 3. Concentration of free fatty acids (FFA) in blood (average values \pm SD) marked at rest before and after "aerobics" on three test terms in the experimental group (I, II, III), and in the control group (IC, IIIC). I (IC)- at the beginning, II - after 6 weeks, III (IIIC) - at the end (12 ${ }^{\text {th }}$ week) of experiment. 


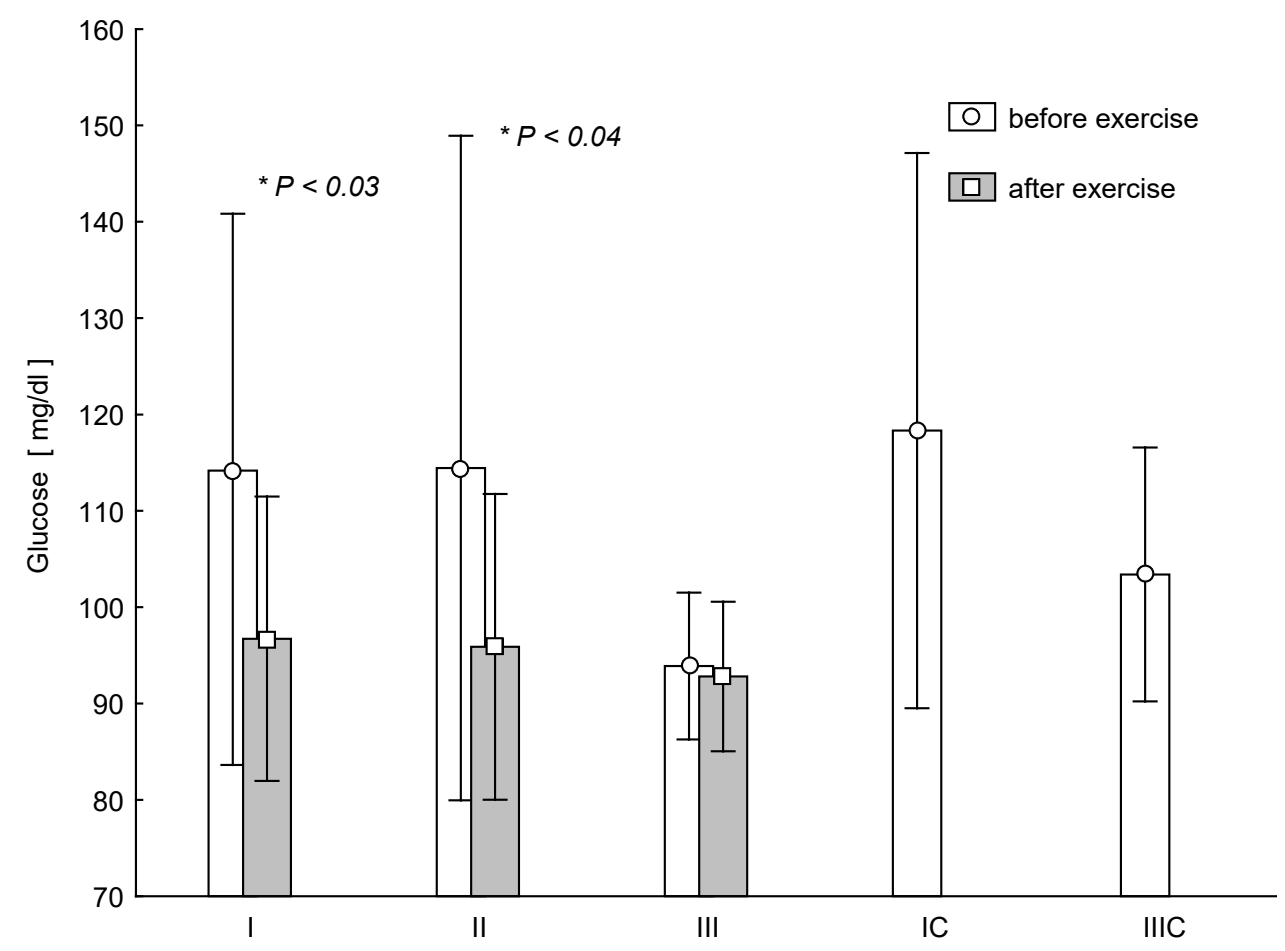

Figure 4. Concentration of glucose in blood (average values \pm SD) marked at rest before and after "aerobics" on three test terms in the experimental group (I, II, III), and in the control group (IC, IIIC). I (IC) - at the beginning, II - after 6 weeks, III (IIIC) - at the end (12 ${ }^{\text {th }}$ week) of experiment.

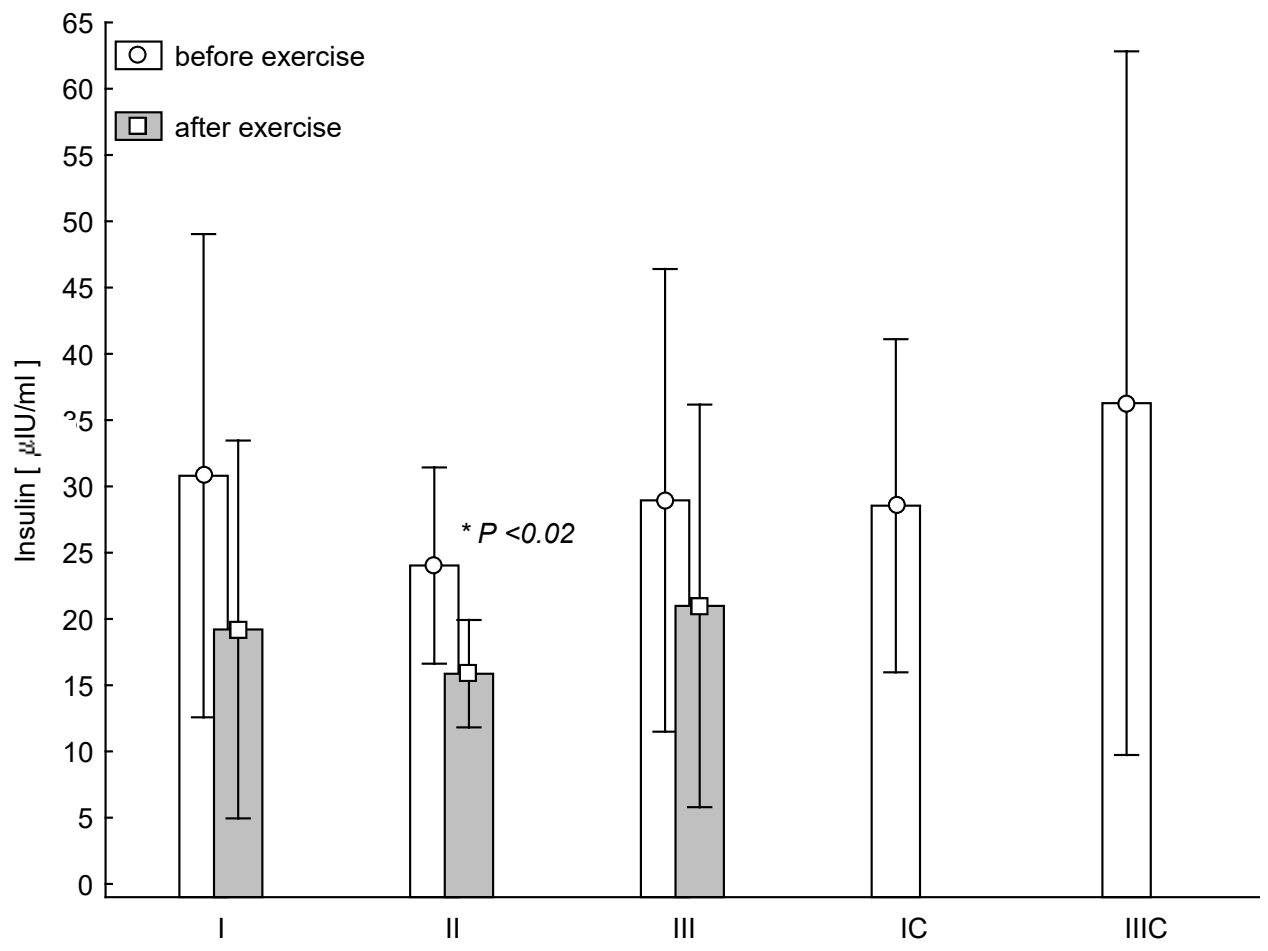

Figure 5. Concentration of insulin in blood (average values \pm SD) marked at rest before and after "aerobics" on three test terms in the experimental group (I, II, III), and in the control group (IC, IIIC). I (IC)- at the beginning, II - after 6 weeks, III (IIIC) - at the end (12 ${ }^{\text {th }}$ week) of experiment. 


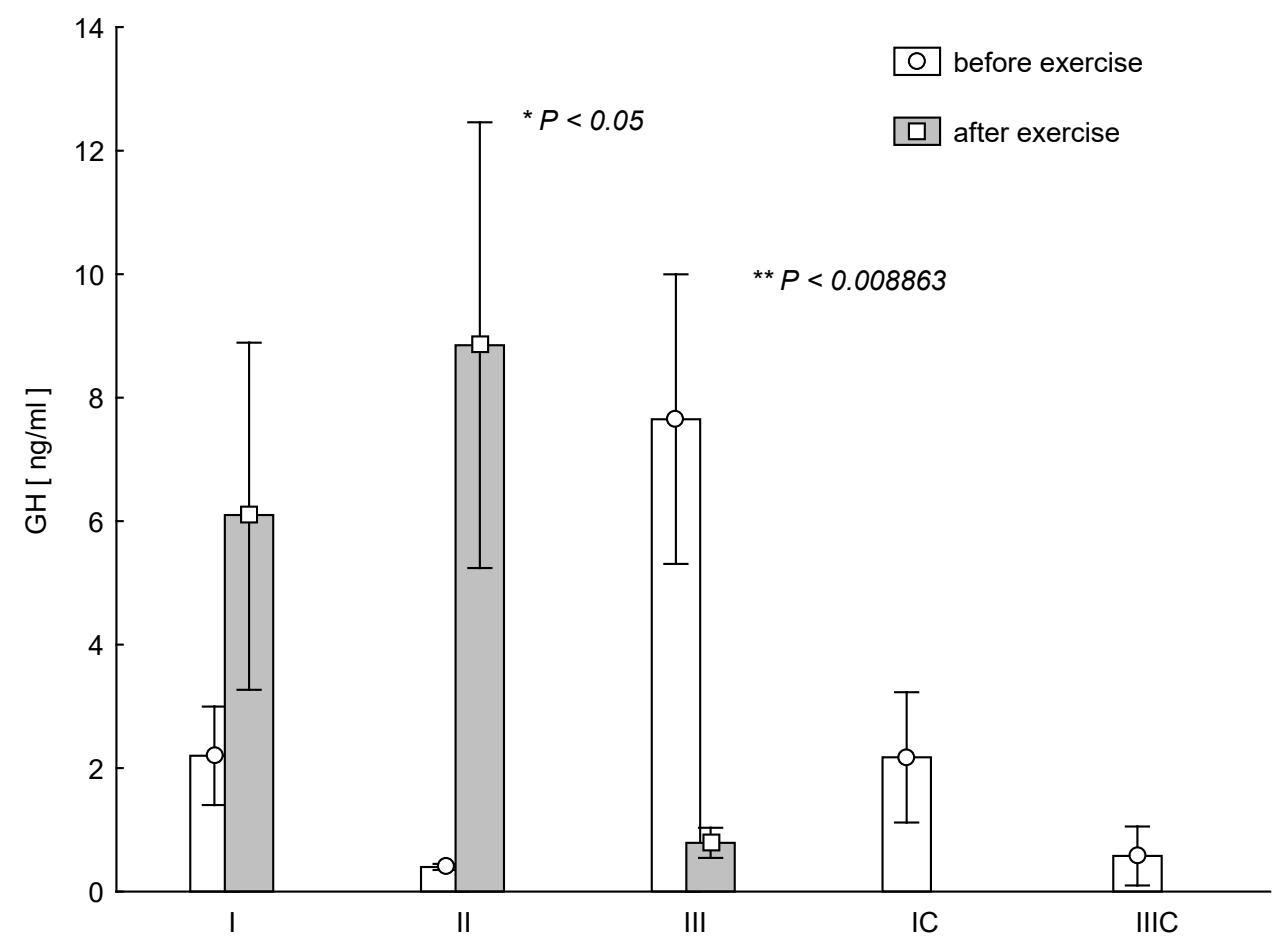

Figure 6. Concentration of growth hormone (GH) in blood (average values \pm SE) marked at rest before and after "aerobics" on three test terms in the experimental group (I, II, III), and in the control group (C, IIIC). I (IC)- at the beginning, II - after 6 weeks, III (IIIC) - at the end (12 ${ }^{\text {th }}$ week) of experiment.

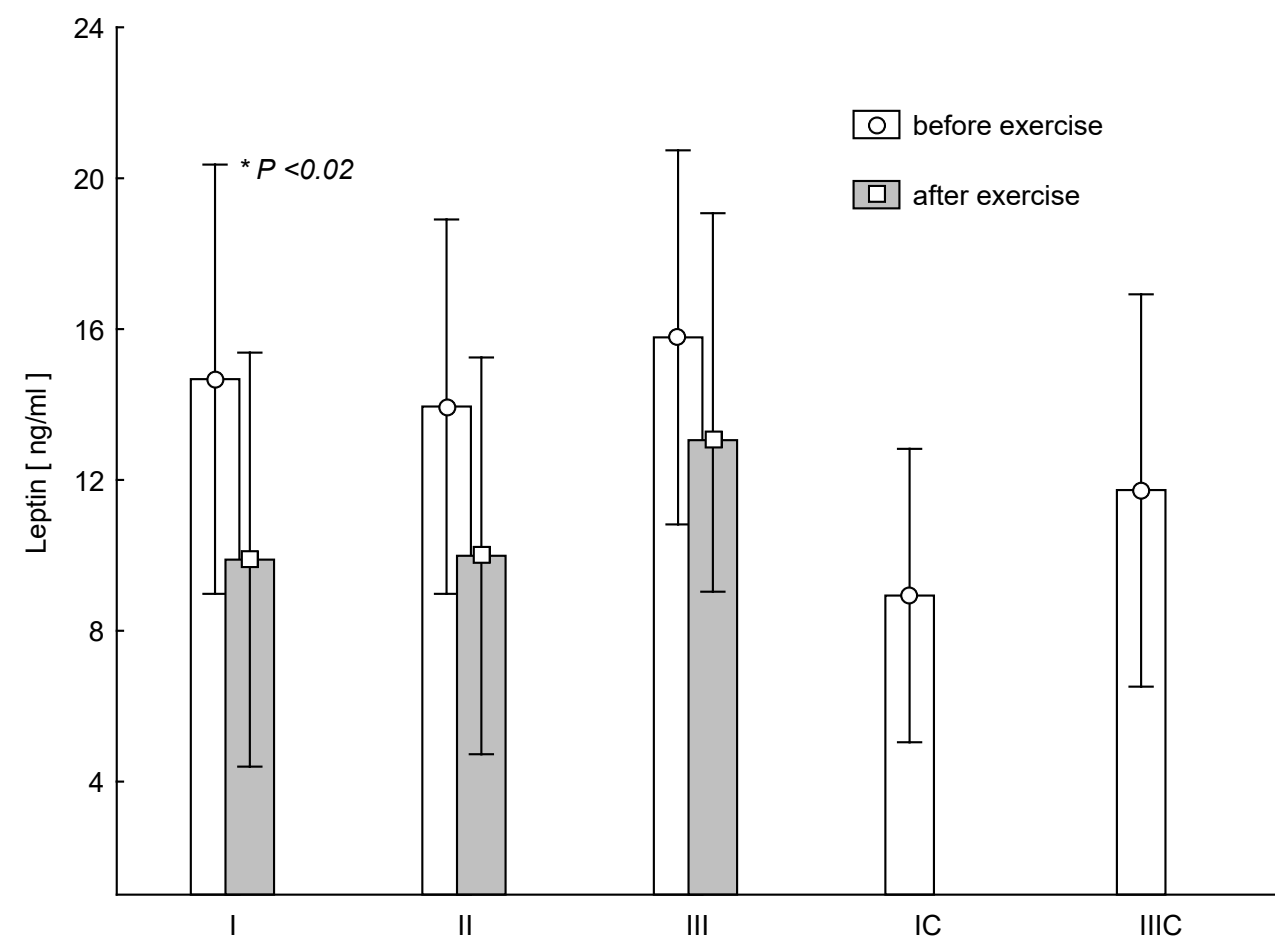

Figure 7. Concentration of leptin in blood (average values \pm SD) marked at rest before and after "aerobics" on three test terms in the experimental group (I, II, III), and in the control group (IC, IIIC). I (IC)- at the beginning, II - after 6 weeks, III (IIIC) - at the end (12 ${ }^{\text {th }}$ week) of experiment. 


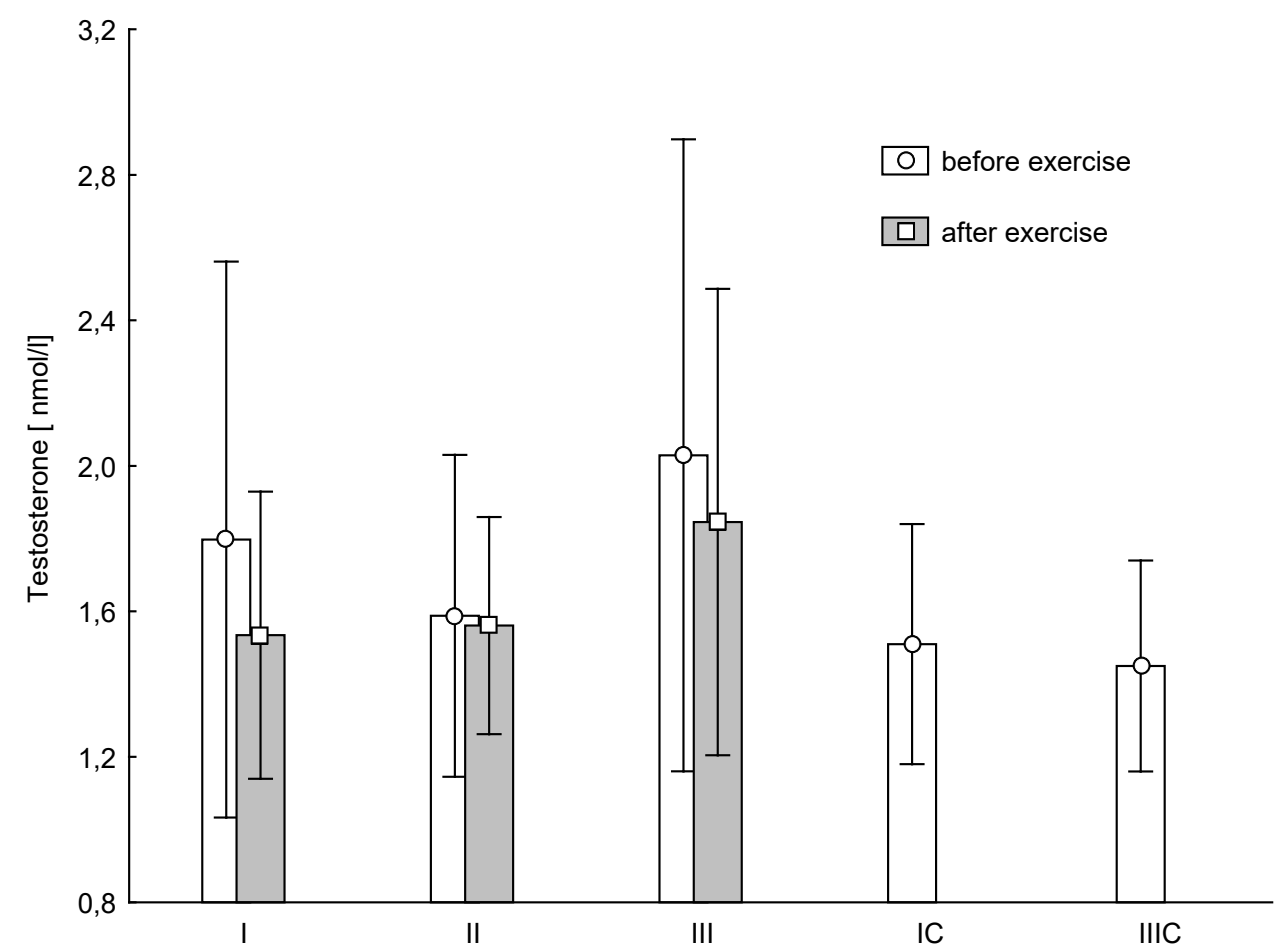

Figure 8. Concentration of testosterone in blood (average values \pm SD) marked at rest before and after "aerobics" on three test terms in the experimental group (I, II, III), and in the control group (C, IIIC). I (IC) - at the beginning, II - after 6 weeks, III (IIIC) - at the end (12 week) of experiment.

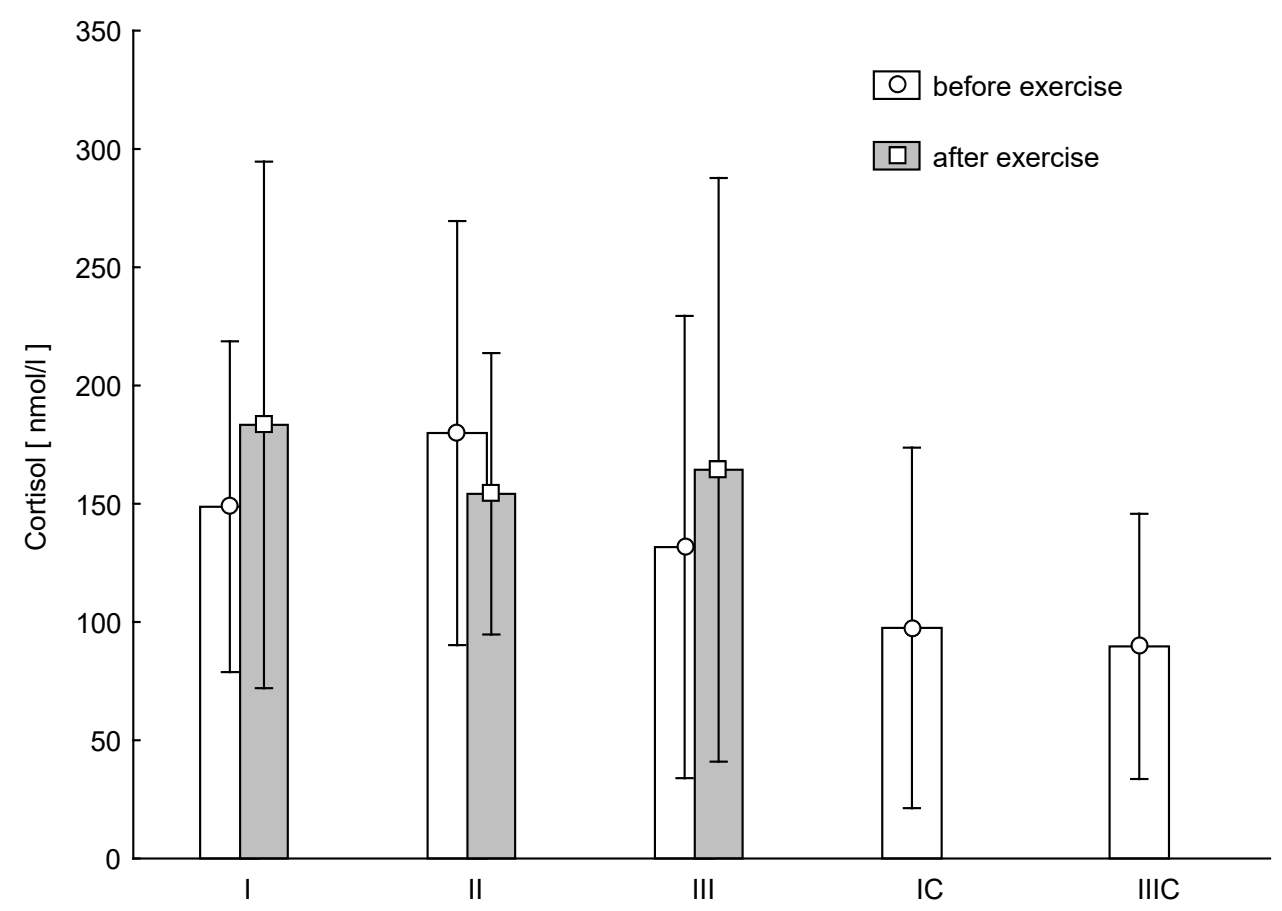

Figure 9. Concentration of cortisol in blood (average values \pm SD) marked at rest before and after "aerobics" on three test terms in the experimental group (I, II, III), and in the control group (C, IIIC). I (IC) - at the beginning, II - after 6 weeks, III (IIIC) - at the end (12 $2^{\text {th }}$ week) of experiment. 
Table 2. Mean $( \pm$ SD) rest values of metabolic and hormone parameters determined for the experimental $(\mathrm{n}=13)$ and the control group $(\mathrm{n}=12)$ at the beginning $(\mathrm{I})$, after 6 weeks $(\mathrm{II})$ and 12 weeks (III) of experiment. IC and IIIC - data for the control group

\begin{tabular}{|c|c|c|c|c|c|c|c|c|c|c|}
\hline \multirow{2}{*}{ parameter } & \multicolumn{6}{|c|}{ Experimental group } & \multicolumn{4}{|l|}{ Control group } \\
\hline & I & range & II & range & III & range & IC & range & IIIC & range \\
\hline $\begin{array}{l}\text { Lactic acid } \\
(\mathrm{mmol} / \mathrm{l})\end{array}$ & $1.093 \pm 0.464$ & $0.06 \div 1.71$ & $1.185 \pm 0.352$ & $0.742 \div 1.720$ & $1.001 \pm 0.602$ & $0.520 \div 2.620$ & $1.4 \pm 0.4$ & $1.1 \div 2.8$ & $1.3 \pm 0.6$ & $1.1 \div 2.9$ \\
\hline $\begin{array}{l}\text { Glucose } \\
(\mathrm{mg} / \mathrm{dl})\end{array}$ & $112.2 \pm 28.6$ & $82.0 \div 173.0$ & $114.4 \pm 34.5$ & $78.0 \div 185.0$ & $93.9 \pm 7.62$ & $80.0 \div 106.0$ & $118.3 \pm 28.8$ & $76.0 \div 161.0$ & $103.4 \pm 13.2$ & $84.0 \div 124.0$ \\
\hline $\begin{array}{l}\text { Free fatty acid } \\
(\mathrm{mmol} / \mathrm{l})\end{array}$ & $0.332 \pm 0.281$ & $0.117 \div 1.052$ & $0.218 \pm 0.145$ & $0.039 \div 0.584$ & $0.308 \pm 0.212$ & $0.039 \div 0.623$ & $0.243 \pm 0.087$ & $0.117 \div 0.390$ & $0.137 \pm 0.138$ & $0.039 \div 0.234$ \\
\hline $\begin{array}{l}\text { Insulin } \\
(\mu \mathrm{IU} / \mathrm{ml})\end{array}$ & $30.806 \pm 18.235$ & $11.843 \div 73.309$ & $24.028 \pm 7.407$ & $12.694 \div 32.848$ & $28.943 \pm 17.455$ & $7.413 \div 52.616$ & $28.541 \pm 12.567$ & $10.028 \div 43.387$ & $36.279 \pm 26.545$ & $15.697 \div 88.684$ \\
\hline $\begin{array}{l}\text { Growth hormone } \\
(\mathrm{ng} / \mathrm{ml})\end{array}$ & $2.2 \pm 2.89$ & $0.3 \div 8.9$ & $0.4 \pm 0.2$ & $0.2 \div 0.7$ & $7.7 \pm 7.4 b^{*} c^{*}$ & $1.0 \div 26.5$ & $2.2 \pm 3.0$ & $0.3 \div 7.2$ & $0.6 \pm 0.5 \mathrm{c}^{*}$ & $0.3 \div 1.9$ \\
\hline $\begin{array}{l}\text { Testosterone } \\
(\mathrm{nmol} / \mathrm{ml})\end{array}$ & $1.80 \pm 0.76$ & $1.21 \div 3.47$ & $1.59 \pm 0.44$ & $1.18 \div 2.60$ & $2.03 \pm 0.87 b^{*} c^{*}$ & $1.28 \div 3.30$ & $1.51 \pm 0.33$ & $1.21 \div 2.08$ & $1.42 \pm 0.29$ & $1.14 \div 1.98$ \\
\hline $\begin{array}{l}\text { Cortisol } \\
(\mathrm{nmol} / \mathrm{l})\end{array}$ & $149 \pm 73$ & $36 \div 248$ & $180 \pm 90 a^{*}$ & $72 \div 331$ & $132 \pm 98 b^{*}$ & $28 \div 317$ & $98 \pm 76$ & $50 \div 276$ & $90 \pm 56$ & $30 \div 221$ \\
\hline $\begin{array}{l}\text { Leptin } \\
(\mathrm{ng} / \mathrm{ml})\end{array}$ & $14.478 \pm 5.698$ & $5.380 \div 23.784$ & $14.597 \pm 4.960$ & $7.690 \div 22.526$ & $15.780 \pm 4.959$ & $8.428 \div 22.538$ & $8.933 \pm 3.889$ & $5.112 \div 14.276$ & $11.731 \pm 5.198$ & $5.360 \div 20.008$ \\
\hline
\end{tabular}

* values significantly different $(p<0.05) ; a-I$ vs. II; $b-I I$ vs. III; $c-I$ vs. III

tests II and III, post-exercise LA increase was statistically significant $(p<0.05)$. LA absolute values and changes in HR show a low degree of metabolic acidosis and indicate the oxygen nature of the energy of exercise performed. The increased concentration of LA, both on tests II and III in comparison with the test I (beginning of the experiment) was statistically significantly higher ( $p=0.011$ and $p=0.005$ respectively).

Analysis of changes in the examined metabolic-hormonal parameters at rest in the EG (Table 2) revealed that the 12-week aerobic training resulted in a decrease in blood GLU, FFA, INS and C and increase in concentration of GH, T and LEP. T, C, and GH changes were statistically significant $(p<0.05)$. In the case of the CG at the same time, decrease the concentration of GLU, FFA, GH, T, C and increased concentrations of INS and the LEP were recorded. Only GH changes were a statistically significant $(p<0.05)$.

Analysis of metabolic parameters at any time of the research showed statistically insignificant post-exercise increase of FFA in the blood of the women with a clear tendency to reduce these changes during the experiment (Figure 3). Post-exercise GLU, the decrease in the concentration of this parameter (Figure 4) was observed. And the changes in test term I and II later proved to be statistically significant $(p<0.03$ and $p<0.04)$ (Figure 4$)$. It should be noted that changing the concentration of GLU in the test term III was significantly lower in comparison with term II $(p=0.026)$.

It was noted that one-hour exercise resulted at any time of the study in the decrease in the concentration of INS in the blood. These changes were statistically significant in the test II (Figure 5). Based on statistical analysis it was found that the decrease in the concentration of INS in the test term III was smaller than in test term I $(p=0.018)$. The opposite trend than that of the INS, was observed for GH. At the same time, in the case of test II, the GH increase was statistically significant $(p<$ 0.05 ), while in test III we observed its post-exercise significant decrease at the highest average concentration at rest with reference to test I and II (Figure 6). It was found that the increase in post-exercise GH in test term I was the smallest as compared to II $(p=0.006)$.

Figure 7 shows the changes of LEP concentration during the individual training sessions at every stage of research. Post-effort decrease in LEP concentration was observed at any time of the study. It turned out that at test term I the change was statistically significant $(p<0.02)$. There were no statistically significant changes in the post- exercise concentrations $\mathrm{T}$ (Figure 8) and $\mathrm{C}$ (Figure 9) during the experiment. There was an increased concentration of $\mathrm{C}$ in test terms I and III, and its decline in test term II. T-Student test used to determine the significance of changes in the average parameters between the EG and CG groups showed that only in the case of GH, 12-week aerobic exercise showed a statistically significant increase $(p<0.01)$ compared with CG, which showed a decrease in this parameter. The results of Pearson's linear correlation analysis for the interactions between postexercise changes (increase or decrease) in the parameters within EG are shown in table 3.

\section{Discussion}

Physical activity, in addition to food/diet, is one of the most important elements of a healthy lifestyle, and its absence or insufficient quantity can lead to health problems. Physical exercise induces specific metabolic and hormonal changes, which also persist during the restitution [11]. Searching for explanations of such changes lead to the complementary regulation of the persistent image of the body homeostasis. The range of such changes depends on the intensity and duration of either a single physical effort, as well as the entire training process. The role of physical activity as one of the important factors governing the body's energy economy should be emphasized here, i.e. maintaining a constant body weight and its components. This role is particularly played by exercise of moderate intensity and relatively long duration (30-60 $\mathrm{min}$ ), i.e. such an effort, where the processes responsible for the reproduction of resources of ATP in cells are aerobic ones. The main substrates used in these processes are fatty acids, which in turn leads to a reduction of the adipose tissue in total bodyweight [12].

The systems governing the exercise metabolism include the endocrine system and its impact through the humoral transmitters on the mobilization and utilization of energy substrates during muscle work, physical exercise of different structure/form and strength [13]. Physical training has an impact on the processes of adaptation to physical effort. This is accomplished by systematically repeated physical exercises. Complete information about the functional state of the body's response to startup/training load is provided by the measurements and analysis of changes in many indicators - physiological, biochemical and hormonal.

Changes in peripheral (blood) concentrations of certain hormones may provide objective information about the biological effects of 
Table 3. Pearson's linear correlation coefficients $(n=13)$ between the increase/decrease $(\Delta)$ of analyzed parameters noted during aerobic session in 3 test terms $(I-$ at the beginning, II after 6 weeks; III $-12^{\text {th }}$ week); bolded values are statistically significant for $P<0,05$. LA - lactic acid, GLU - glucose, FFA - free fatty acids, INS - insulin, C - cortisol, T - testosterone, $\mathrm{GH}$ - growth hormone

\begin{tabular}{|c|c|c|c|c|c|c|c|c|c|c|c|c|c|c|c|c|c|c|c|c|c|c|c|c|}
\hline & $\begin{array}{l}\Delta \Lambda \mathrm{A} \\
\mathrm{I}\end{array}$ & $\begin{array}{l}\Delta \Lambda \mathrm{A} \\
\text { II }\end{array}$ & $\begin{array}{l}\Delta \Lambda \mathrm{A} \\
\mathrm{III}\end{array}$ & $\begin{array}{l}\Delta \Gamma \Lambda \mathrm{Y} \\
\mathrm{I}\end{array}$ & $\begin{array}{l}\Delta \Gamma \Lambda \\
\mathrm{II}\end{array}$ & $\begin{array}{l}\Delta \Gamma \Lambda \\
\text { III }\end{array}$ & $\begin{array}{l}\Delta \Phi \Phi A ~ \\
\text { I }\end{array}$ & $\begin{array}{l}\Delta \Phi \Phi A \\
\text { II }\end{array}$ & $\begin{array}{l}\Delta \Phi \Phi А ~ \\
\text { III }\end{array}$ & $\begin{array}{l}\Delta \Lambda \mathrm{E} \Pi \\
\mathrm{I}\end{array}$ & $\begin{array}{l}\Delta \Lambda \mathrm{E} \Pi \\
\text { II }\end{array}$ & $\begin{array}{l}\Delta \Lambda \text { EП } \\
\text { III }\end{array}$ & $\begin{array}{l}\Delta \mathrm{IN} \Sigma \\
\mathrm{I}\end{array}$ & $\begin{array}{l}\Delta \mathrm{IN} \Sigma \\
\mathrm{II}\end{array}$ & $\begin{array}{l}\Delta \mathrm{IN} \Sigma \\
\mathrm{III}\end{array}$ & $\begin{array}{l}\Delta \mathrm{X} \\
\mathrm{I}\end{array}$ & $\begin{array}{l}\Delta \mathrm{X} \\
\mathrm{II}\end{array}$ & $\begin{array}{l}\Delta \mathrm{X} \\
\mathrm{III}\end{array}$ & $\begin{array}{l}\Delta \mathrm{T} \\
\mathrm{I}\end{array}$ & $\begin{array}{l}\Delta \mathrm{T} \\
\mathrm{II}\end{array}$ & $\begin{array}{l}\Delta \mathrm{T} \\
\mathrm{III}\end{array}$ & $\begin{array}{l}\Delta \Gamma \mathrm{H} \\
\mathrm{I}\end{array}$ & $\begin{array}{l}\Delta \Gamma \mathrm{H} \\
\text { II }\end{array}$ & $\begin{array}{l}\Delta \Gamma \mathrm{H} \\
\mathrm{III}\end{array}$ \\
\hline$\Delta \Lambda \mathrm{A} \mathrm{I}$ & 1,00 & 0,07 & $-0,06$ & 0,47 & 0,00 & $-0,41$ & $-0,07$ & 0,47 & 0,10 & $-0,21$ & $-0,25$ & $-0,20$ & 0,47 & 0,36 & 0,25 & 0,20 & 0,16 & $-0,46$ & $-0,20$ & $-0,21$ & $-0,10$ & 0,23 & 0,00 & 0,18 \\
\hline$\Delta \Lambda \mathrm{A} I \mathrm{II}$ & & 1,00 & 0,47 & $-0,22$ & $-0,01$ & $-0,12$ & $-0,25$ & 0,03 & 0,07 & $-0,18$ & $-0,13$ & 0,16 & $-0,09$ & 0,07 & 0,03 & $-0,21$ & 0,07 & $-0,38$ & 0,03 & 0,02 & $-0,26$ & 0,66 & 0,55 & $-0,01$ \\
\hline$\Delta \Lambda \mathrm{A}$ III & & & 1,00 & $-0,37$ & $-0,45$ & 0,09 & 0,10 & $-0,45$ & 0,05 & $-0,09$ & 0,19 & 0,32 & 0,01 & $-0,04$ & $-0,18$ & $-0,33$ & $-0,01$ & 0,07 & 0,16 & 0,29 & $-0,08$ & 0,26 & 0,39 & $-0,19$ \\
\hline$\Delta \Gamma \Lambda \mathrm{Y} \mathrm{I}$ & & & & 1,00 & $-0,04$ & $-0,53$ & 0,08 & 0,45 & $-0,34$ & 0,14 & 0,06 & $-0,35$ & 0,28 & $-0,27$ & $-0,22$ & 0,10 & $-0,05$ & $-0,30$ & $-0,24$ & $-0,25$ & 0,30 & 0,14 & $-0,08$ & 0,11 \\
\hline$\Delta \Gamma \Lambda \mathrm{Y}$ II & & & & & 1,00 & $-0,20$ & 0,20 & 0,13 & 0,08 & 0,24 & $-0,11$ & $-0,40$ & $-0,07$ & $-0,26$ & 0,54 & 0,00 & 0,09 & 0,04 & $-0,24$ & $-0,28$ & 0,07 & $-0,52$ & $-0,14$ & 0,41 \\
\hline$\Delta \Gamma \Lambda \mathrm{Y}$ III & & & & & & 1,00 & $-0,24$ & $-0,47$ & $-0,27$ & $-0,33$ & $-0,37$ & 0,22 & $-0,10$ & $-0,12$ & 0,36 & 0,04 & 0,00 & 0,32 & 0,26 & 0,16 & $-0,08$ & $-0,09$ & 0,52 & $-0,77$ \\
\hline$\Delta$ ФФА I & & & & & & & 1,00 & 0,13 & $-0,07$ & 0,59 & 0,21 & $-0,02$ & $-0,08$ & $-0,05$ & $-0,29$ & 0,11 & 0,70 & 0,15 & 0,08 & 0,38 & 0,39 & $-0,25$ & $-0,18$ & 0,40 \\
\hline$\Delta$ ФФА II & & & & & & & & 1,00 & 0,13 & 0,36 & $-0,15$ & $-0,11$ & 0,15 & 0,28 & 0,08 & 0,27 & 0,32 & $-0,64$ & $-0,11$ & 0,23 & 0,22 & 0,41 & $-0,25$ & 0,46 \\
\hline 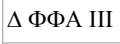 & & & & & & & & & 1,00 & 0,30 & 0,36 & 0,50 & 0,28 & 0,38 & 0,11 & 0,06 & $-0,07$ & 0,25 & 0,23 & 0,26 & 0,25 & $-0,05$ & $-0,34$ & 0,43 \\
\hline$\Delta \Lambda$ ЕП I & & & & & & & & & & 1,00 & 0,54 & 0,34 & $-0,16$ & $-0,15$ & $-0,15$ & $-0,24$ & 0,33 & 0,24 & $-0,04$ & 0,57 & 0,71 & $-0,04$ & $-0,25$ & 0,54 \\
\hline$\Delta \Lambda$ EП II & & & & & & & & & & & 1,00 & 0,58 & 0,15 & $-0,10$ & $-0,46$ & $-0,65$ & $-0,11$ & 0,59 & 0,36 & 0,43 & 0,49 & $-0,05$ & $-0,41$ & 0,52 \\
\hline$\Delta \Lambda$ ЕП III & & & & & & & & & & & & 1,00 & 0,20 & 0,22 & $-0,19$ & $-0,44$ & 0,19 & 0,52 & 0,60 & 0,74 & 0,44 & 0,38 & 0,13 & 0,06 \\
\hline$\Delta \mathrm{IN} \Sigma \mathrm{I}$ & & & & & & & & & & & & & 1,00 & $-0,12$ & 0,25 & 0,11 & $-0,07$ & 0,13 & 0,62 & 0,16 & 0,46 & $-0,02$ & 0,06 & $-0,03$ \\
\hline$\Delta \mathrm{IN} \Sigma \mathrm{II}$ & & & & & & & & & & & & & & 1,00 & $-0,16$ & 0,26 & 0,31 & $-0,21$ & 0,03 & 0,03 & $-0,46$ & 0,32 & $-0,35$ & 0,31 \\
\hline$\Delta \mathrm{IN} \Sigma$ III & & & & & & & & & & & & & & & 1,00 & 0,12 & $-0,15$ & $-0,06$ & $-0,06$ & $-0,14$ & 0,03 & $-0,27$ & 0,30 & $-0,22$ \\
\hline$\Delta \mathrm{X} \mathrm{I}$ & & & & & & & & & & & & & & & & 1,00 & 0,12 & $-0,33$ & $-0,06$ & $-0,33$ & $-0,16$ & $-0,15$ & $-0,06$ & $-0,23$ \\
\hline$\Delta \mathrm{X}$ II & & & & & & & & & & & & & & & & & 1,00 & $-0,09$ & 0,13 & 0,47 & 0,17 & 0,21 & 0,13 & 0,26 \\
\hline$\Delta \mathrm{X}$ III & & & & & & & & & & & & & & & & & & 1,00 & 0,42 & 0,21 & 0,42 & $-0,49$ & $-0,07$ & $-0,07$ \\
\hline$\Delta \mathrm{T} \mathrm{I}$ & & & & & & & & & & & & & & & & & & & 1,00 & 0,52 & 0,39 & 0,11 & 0,07 & $-0,05$ \\
\hline$\Delta \mathrm{T}$ II & & & & & & & & & & & & & & & & & & & & 1,00 & 0,60 & 0,32 & 0,06 & 0,18 \\
\hline$\Delta \mathrm{T}$ III & & & & & & & & & & & & & & & & & & & & & 1,00 & $-0,07$ & 0,05 & 0,13 \\
\hline$\Delta \Gamma \mathrm{H} \mathrm{I}$ & & & & & & & & & & & & & & & & & & & & & & 1,00 & 0,39 & $-0,05$ \\
\hline$\Delta$ ГН II & & & & & & & & & & & & & & & & & & & & & & & 1,00 & $-0,70$ \\
\hline$\Delta \Gamma \mathrm{H} \mathrm{III}$ & & & & & & & & & & & & & & & & & & & & & & & & 1,00 \\
\hline
\end{tabular}

physical load applied. Adaptation to physical exercise occurring under the influence of exercise represents a biological substrate of the overall physical capacity resulting from a specificity of sport practiced.

During prolonged muscular work (here: aerobic lasting 60 minutes), muscle energy demand is almost satisfied by aerobic processes. Cardio-respiratory circuit fully ensures the availability of oxygen to working muscles, and production of LA in this situation is very small. LA concentration in the blood, which may increase depending on the intensity of exercise, is reduced as far as the work is continued. Significant amounts of this compound are converted into glucose in the liver and part of the lactate is oxidized in the myocardium and skeletal muscles [14]. Such a picture can be observed during the present experiment. Concerning changes in HR and LA, the aerobic nature of exercises and training applied can be clearly seen, and manifestation of adaptation of the e.g. circulatory system includes lower HR course during the test III.

One-hour exercise resulted in a significant decrease in GLU in the blood in tests I and II. Similar results were obtained by Colberg et al. [15] who observed a decrease in GLU concentration after exercise intensities combined and moderate exercise. In our study in the test III, i.e. after the 12-week training, there were no significant differences. This could be an interesting effect of training, which is probably associated with the fact of "stabilization" of blood glucose of regularly exercising women, i.e. a hormonal mechanism for the protection/conservation reserves of glucose in the peripheral blood stream. This effect can also reveal low levels of glucose before the start of aerobics session, which in turn may indicate high resting levels of GH. Hypoglycemia is a potent factor in stimulating the secretion of GH. At the same time, it must be emphasized that the GLU concentration values are within the normal reference ranges. Analysing the value of rest values, we noted negligible decrease in the concentration of GLU. Our results agree with the results of Wiklund et al. [16] who have observed such changes in women aged $41.5( \pm 7.6)$ years under the influence of 6-week training of Nordic walking.

The share of FFA in satisfying the energy demand for working muscles increases progressively during exercise and along with the effort duration can be about $80 \%$ of the total energy expenditure in training session [17]. At the same time, it must be emphasized that the role of carbohydrate substrates (glucose, glycogen) is, to a lesser extent, preserved. In this study the concentration of FFA shows the reverse course than in the case of GLU, i.e. a post-exercise increases of blood FFA on each test term (I - a statistically significant change). After training, i.e. in the test III, these changes seem to be getting smaller. Reduction of exercise-induced increase in FFA concentrations observed during the test III may suggest the increase in tissue uptake of these compounds. This is undoubtedly related to better blood circulation in the working 
muscles and to increase of more effective extraction of oxygen from flowing blood under the influence of training. Our observations are confirmed by the work of Chen et al. [18] who reported that $60 \mathrm{~min}$. walking exercise at an intensity of $60 \% \mathrm{VO}_{2 \max }$ resulted in a statistically significant increase of FFA [18].

There was no significant change in the concentrations of $\mathrm{C}$ and $\mathrm{T}$ in the blood. However, 1-hour aerobic training has caused a response of GH, i.e. its increase after exercise, but just in case of test term I and II. In the test term III the GH decrease was observed after an hour of exercise. Reverse changes relate to the insulin (INS) and leptin (LEP). Every exercise analyzed in three test terms showed a decline of these hormones after the session. Hormones such as INS and GH are counter-regulative hormones for GLU. Hour effort resulted in a decrease in blood levels of INS and the increased concentration of GH. Confirmation of these relationships includes negative correlations between them (Table 3). According to the literature, GH 'blocks' GLU uptake by skeletal muscles, while the INS facilitates this process [13]. In the context of glucostatic processes, the behaviour of these two hormones shows the hormonal mechanism of physiological regulation of energy substrate availability, securing the long-term physical activity.

INS concentration in the blood decreases during exercise of already the intensity of $30-40 \% \mathrm{VO}_{2 \max }$ and when it is a long-term effort. One of the mechanisms of its reduction during exercise may be associated with the mechanism of inhibition of its secretion by catecholamines. Another mechanism may involve its increased capture and distribution in skeletal muscles. There are data that show the reduction of its effort decrease under the influence of physical training [19]. This effect can be associated with a decreased stress response of the sympatheticadrenal system. Reduction in the concentration of INS in the blood during exercise inhibits glycogenolysis and gluconeogenesis in the liver and the release of FFA from adipose tissue. This means greater mobilization of energy substrates outside the muscle. Mainly it is a fatty tissue. Moreover, the decrease in blood levels of INS causes less GLU use by, for example, adipose tissue, not working muscles. This allows for maintaining of GLU for the nervous system (brain) and the working muscles. Our studies show such relationships. This is the right image of adaptation to regularly conducted physical exercises. Similar results were obtained in their experiments by Wiklund et al. [16].

Exercise is a potent physiological stimulus for the burst of GH. Its secretion is increased when the exercise duration and intensity reach a certain threshold value [19]. Increased cholesterol in the blood is observed when in the effort energy the anaerobic glicolitic-lactate processes prevail, leading to a state of significant metabolic acidosis. Also, the increase of body temperature induced by exercise is one of the factors increasing its secretion. Apart from lypolytic impact on adipose tissue, GH also influences the inhibition of GLU uptake by skeletal muscles; it is involved in thermoregulatory processes by influencing the hydromeiosis (relation to eccrine sweat glands). It also has an anabolic effect on the muscle tissue. The form and type of exercise, its duration and intensity, phase of the training cycle, and environmental conditions in which work is carried out may affect the size of the GH burst [19]. In our study anaerobiosis had no significant effect on its burst. Observed post-exercise decrease in plasma concentrations of $\mathrm{GH}$ in the test III shows the modulating effect of 12 weeks of training on GH circulation. Data from the literature emphasize reduction of GH level after the training cycle, especially of strength and endurance, which in turn stimulates the development of aerobic energy processes [20]. It may also be related to a greater influence on the adrenergic stimulation of lipolysis during the hours of effort and inhibition of $\mathrm{GH}$ secretion by FFA. Also, the state of pre-exercise glycaemia could affect this concentration during rest examination, i.e. before aerobics. In our opinion the observed relationships require further study.

Moderate, prolonged physical activity, performed at around $60 \%$ of maximum heart rate, affect the increase in overall energy use of the FFA and was characterized by a decrease in the use of GLU. This is associated with the regulatory influence of growth hormone on energy use and consequently may lead to physiological weight loss, mainly fatty tissue. In our study weight loss was observed after 6 weeks of training (test II).

Applied training did not impair anabolic-catabolic balance. Concentrations of testosterone (T) and cortisol (C) did not indicate a metabolic imbalance. This means that used in the literature [21] anabolic-catabolic indicator, i.e. the ratio of testosterone to cortisol was not subject to a significant disturbance. Androgenic-glucocorticoid status was preserved, and it emphasizes the fact that training was used optimally.

In the case of tests, I and III, the studies showed higher post-exercise concentrations of $\mathrm{C}$, while in test II the change was smaller. Beside the known catabolic action cortisol is also a classic effort stress hormone and under the influence of systematic training its poor response to exercise at submaximal intensity can also be seen. It was also found that exercise increases the rate of cortisol "removal" from the blood [22].

An interesting fact of our observation, although statistically insignificant, is an increase in T levels during the test III in women of EG. It is well known that $\mathrm{T}$, in addition to androgenic action, is a potent stimulator of anabolic processes in skeletal muscles [23]. The average, $\mathrm{T}$ concentration at rest in the EG in the test III was higher than in women of CG. This implies a possible increase in fat free mass (FFM), and therefore increase in muscle strength. Analysis of body composition components of the women confirmed our suspicions (data not presented in this paper).

Leptin (LEP) test at any time after a session of aerobics exhibited lower concentrations. It is a signal to the central nervous system about the decrease in system energy reserves caused by intensive work of skeletal muscles during a training session [24]. During the entire 12 weeks of training, the levels determined at rest before the aerobics in the EG did not show significant changes. Leptin secreted by adipose tissue exerts inhibitory effects on appetite [25]. In our study, the concentration of LEP at rest showed a relatively constant level. Conducted 12-week training had no apparent effect on leptin secretion. As it is known the concentration of leptin in the blood increases with increasing fat mass and decreases with its decreasing. The obtained results show, among others, lower blood concentrations at rest in not-practicing women than in the experimental group, although the differences between the groups were not statistically significant. Literature reports on the behaviour of leptin under the influence of training are not clear. Abedi observed that an acute aerobic exercise (a treadmill, $30 \mathrm{~min}$.) and resistance exercise (70\% of one repetition maximum, 10 repetition, 3 rounds) caused reducing serum leptin concentration [26]. In contrast, Shalitin at al. [27] who analysed 12-week aerobic training, Lambert at al. who analysed 12-week resistance training and Lucotti et al. [28] who analysed 3-week combined aerobic and resistance training noted no change in leptin levels [27-29].

In our study we did not control the daily energy balance, we did not analyse diet used by the examined women, and we based only on data relating to changes in total body weight. Undoubtedly, an important 
complement to the data presented would be a body composition analysis of the women in both groups. However, due to a range of issues of this study, changes in body composition will be presented in our next paper (unpublished observation). In the implementation of such training it is important to determine the amount of physical loading (training), the supply of energy (calories) in relation to activities of daily living and leisure. Therefore, assessment of the role of leptin in our study has some limitations. Nevertheless, the reduction was confirmed after an hour of effort with no clear trend throughout the 12-week observation period, with little indication of a smaller decline during the test III.

\section{Conclusions}

The applied exercise stimulus 3 times weekly, lasting 60 minutes was the optimal stimulus for the maintenance of normal/health ratio between body weight and height. Adipose tissue in the experimental group remained stable and was lower than in the control group women (unpublished observation). Training did not cause hormonal imbalance, while maintaining the stimulation of $\mathrm{GH}$, which may be important in the overall balance of health and allows for building of a systematic physical exercise factor into healthy lifestyle, in addition to proper diet. Hormonal stimulation is the inner organism signal to the central nervous system. The feeling of tiredness and exhaustion has its roots in biological and hormonal changes and may serve as the first signal to the verification of training/exercises.

Conducted observations emphasize the lower energy cost of exercise performed while improving physical fitness (movement technique) of women who underwent the training. In conclusion, no adverse hormonal reactions, maintaining the anabolic-catabolic balance, stable energy profile and maintaining of similar weight suggest the beneficial effects of training. Reduction of the biological cost of gymnastics along the duration of training increases the exercise tolerance of the exercisers. This represents all aspects of healthy physical activity and is a scientific rationale for using exercise adequate in terms of structure and intensity of movement in relation to gender and age.

\section{Perspective}

Physiological picture of the applied effort model permits for its scientific/objective standardisation during development a healthy life as one of the factors preventing obesity, metabolic disorders and circulatory diseases. The results show also it is possible to become aware of one's own body and to hold control over the amount of physical effort to a certain objective extent.

The results obtained in our study show many aspects of biological cost related to physical effort of a defined structure and duration. In this case it was an hour-long model of physical exercise accompanied by music, which in the context of hormone reactions, does not disturb the secretion "reserves" of the pituitary and adrenal glands. And stimulation of the growth hormone with physical effort is a physiological stimulus for secretion of this hormone, the role of which in old age is yet not fully understood. It particularly regards its relationship with metabolic processes, thermoregulation and dehydration.

\section{Acknowledgment}

Research was financed by the project of Statutory Research Ds. 103. One of the authors M. Ch., would like to express thanks to Professor Toivo Jürimäe from University in Tartu, Estonia for helpful discussion.

\section{References}

1. Baldassarre S, Fragapani S, Panero A, Fedele D; Pinach S et al (2017) NTproBNP in insulinresistance mediated conditions: overweight/obesity, metabolic syndrome and diabetes. The population-based Casale Monferrato Study. Cardiovasc Diabetol 16: 119. [Crossref]

2. El-Eshmawy M, Abdel Aal I (2015) Relationships between preptin and osteocalcin in obese, overweight, and normal weight adults. Appl Physiol Nutr Metab 40: 218-222. [Crossref]

3. Broussard JL, Kilkus JM, Delebecque F, Abraham V, Day A, et al. (2016) Elevated ghrelin predicts food intake during experimental sleep restriction. Obesity (Silver Spring) 24: 132-138. [Crossref]

4. do Carmo JM, Freeman JN, Wang ZM, Sydney P, Hankins MW, et al (2018) Neuronal Suppressor of Cytokine Signaling 3: Role in Modulating Chronic Metabolic and Cardiovascular Effects of Leptin. Hypertension 71: 1248-1257. [Crossref]

5. van Tienhoven-Wind LJ, Dullaart RP (2017) Increased leptin/adiponectin ratio relates to low-normal thyroid function in metabolic syndrome. Lipids Health Dis 16: 1-6. [Crossref]

6. Zamani M, Peeri M, Azarbayjani M, Matinhomaee H (2016) Effects of Resistance Training on Adiponectin, Testosterone and Cortisol Levels in Untrained Men. Medical Laboratory Journal 10: 24-31.

7. Djelic M, Mazic S, Lazovic B, Zikic D, Sumarac-Dumanovic M (2015) Carbohydrate and fatty acid metabolism responses to a graded maximal exercise test and recovery period in athletes and sedentary subjects. Science \& Sports 30: 321.

8. Lee S, Norheim F, Langleite TM, Noreng HJ, Storas TH, et al (2016) Effect of energy restriction and physical exercise intervention on phenotypic flexibility as examined by transcriptomics analyses of mRNA from adipose tissue and whole-body magnetic resonance imaging. Physiological Reports 4: pii: e13019. [Crossref]

9. Charmas M, Opaszowski BH, Charmas R, Różańska D, Jówko E, et al. (2009) Hormone and metabolic response in middle-aged women to moderate physical effort during "aerobics". J Strength Cond Res 23: 954-961. [Crossref]

10. Larose DT (2006) Data mining methods and models, India Pvt Ltd, Wiley.

11. Borer KT, Exercise Endocrinology. Borer KT (Edtr). USA: Human Kinetics: 106-116.

12. McArdle WD (2014) Exercise Physiology, energy, nutrition and human performance. McArdle W.D (Edtr). USA: Lippincott Williams and Wilkins: 774-809.

13. Borer KT (2003) Exercise Endocrinology. Borer K.T (Edtr). USA: Human Kinetics: 39-64.

14. Bonen A (2006) Exercise metabolism, Hargreaves H. \& Spriet L. (Edtr), USA: Human Kinetics: 71-104.

15. Colberg SR, Hernandez MJ, Fatima S (2013) Blood glucose responses to type, intensity, duration, and timing of exercise. Diabetes Care 36: 177. [Crossref]

16. Wiklund P, Alen M, Munukka E, Cheng S, Bo Y (2014) Metabolic response to 6-week aerobic exercise training and dieting in previously sedentary overweight and obese premenopausal women: A randomized trial. J Sport and Health Sci 3: 217-224.

17. Turcotte LP (2006) Exercise metabolism, USA: Human Kinetics, 105-136.

18. Chen YC, Travers RL, Walhin JP1, Gonzalez JT1, Koumanov F, et al (2017) Feeding influences adipose tissue responses to exercise in overweight men. Am J Physiol Endocrinol Metab 313: 84-93. [Crossref]

19. Powers SK, Howley ET (2014) Exercise physiology. Theory and application to fitness and performance, Powers SK, Howley ET. (Edtr.). New York: McGraw-Hill International Edition: 92-105.

20. Eklund D, Schumann M, Kraemer W, Izquierdo M, Taipale R, et al. (2016) Acute endocrine and force responses and long-term adaptations to same-session combined strength and endurance training in women. J Strength Cond Res 30: 164-175. [Crossref]

21. Fothergill M, Wolfson S, Neave N (2017) Testosterone and cortisol responses in male soccer players: The effect of home and away venues. Physiol Behav 177: 215-220. [Crossref]

22. Ghaderi M, Nikbakht H, Chtourou H, Jafari M, Chamari K (2015) Listening to motivational music: lactate and cortisol response to a single circuit resistance exercise for young male athletes. South African J Research Sport 37: 33-45.

23. Ribeiro A, Schoenfeld B, Fleck S, Pina F, Nascimento M, et al. (2017) Effects of Traditional and Pyramidal Resistance Training Systems on Muscular Strength, Muscle Mass, and Hormonal Responses in Older Women: A Randomized Crossover Trial. $J$ Strength Cond Research 31: 1888-1896. [Crossref]

24. Blundell JE, Gibbons C, Caudwell P, Finlayson G, Hopkins M (2015) Appetite control and energy balance: impact of exercise. Obesity Reviews 16: 67-76. [Crossref] 
25. Dodds Wj (2017) Central Nervous System Regulation of Appetite in Humans and Pet Animals. Ann Clin Exp Metabol 2: 1013.

26. Abedi B (2016) The effect of acute aerobic exercise and resistance exercise on leptin serum and insulin resistance index in sedentary men. Yaften 17: 109-119.

27. Shalitin S, Ashkenazi-Hoffnung L, Yackobovitch-Gavan M, Nagelberg N, Karni Y, et al. (2009) Effects of a twelve-week randomized intervention of exercise and/or diet on weight loss and weight maintenance, and other metabolic parameters in obese preadolescent children. Horm Res 72: 287-301. [Crossref]
28. Lambert CP, Sullivan DH, Evans WJ (2003) Effects of testosterone replacement and/ or resistance training on interleukin-6, tumor necrosis factor alpha, and leptin in elderly men ingesting megestrol acetate: a randomized controlled trial. J Gerontol A Biol Sci Med Sci 58: 165-170. [Crossref]

29. Lucotti P, Monti LD, Setola E, Galluccio E, Gatti R, et al. (2011) Aerobic and resistance training effects compared to aerobic training alone in obese type 2 diabetic patients on diet treatment. Diabetes Res Clin Pract 94: 395-403. [Crossref]

Copyright: $\mathbb{C} 2018$ Charmas M. This is an open-access article distributed under the terms of the Creative Commons Attribution License, which permits unrestricted use, distribution, and reproduction in any medium, provided the original author and source are credited. 